\title{
The Values of Eccentricity-Based Topological Indices of Diamond Graphs
}

\author{
Mukaddes ÖKTEN TURACI*1 \\ ${ }^{1}$ Karabuk University, Yenice Vocational School, Department of Computer Programming, 78700, Karabük
}

(Alınış / Received: 01.03.2018, Kabul / Accepted: 25.06.2018, Online Yayınlanma / Published Online: 16.08.2018

\author{
Keywords \\ Graph theory, \\ Vulnerability, \\ Eccentricity, \\ Topological indices, \\ Diamond graphs
}

\begin{abstract}
Graph theory has been studied different areas such as information, mathematics and chemistry sciences. Especially, it has been the most important mathematical tools for the study the analysis of chemistry. A topological index has been a numerical descriptor of the molecular structure derived from the corresponding molecular graph, also it has used vulnerability of chemical graphs. The vulnerability of a graph has been the reliability of the graph after the disruption of some vertices or edges until breakdown. There are a lot of topological indices which have been defined. Furthermore, the diamond graphs have been defined recently. In this paper, exact formulas for the eccentricity-based topological indices of diamond graphs have been obtained.
\end{abstract}

\section{Elmas Grafların Dışmerkezliğe Dayalı Topolojiksel İndekslerinin Değerleri}

\author{
Anahtar Kelimeler \\ Graf teori, \\ Zedelenebilirlik, \\ Dışmerkezlik, \\ Topolojiksel indeksler, \\ Elmas graflar
}

\begin{abstract}
Özet: Graf teori bilgi, matematik ve kimya gibi bilim alanlarında çalıșılmaktadır. Özellikle, kimyasal analiz çalışmaları için en önemli matematiksel araçlardan biridir. Bir topolojik indeks, moleküler yapıdan türetilen bir grafın sayısal tanımlayıcısıdır, ayrıca kimyasal grafların zedelenebilirliği için kullanılır. Bir grafın zedelenebilirliği, grafın bazı tepelerinin ve ayrıtlarının zarar görmesinden sonra grafın dayanıklılığıdır. Tanımlanan bir çok topolojiksel indeks vardır. Bununla beraber, son zamanlarda elmas graflar tanımlanmıştır. Bu çalışmada, elmas grafların dışmerkezliğe dayalı topolojiksel indeksleri için tam sonuçlar elde edilmiştir.
\end{abstract}

\section{Introduction}

Graph theory's diverse applications in natural science (Chemistry, Biology), especially it is becoming an important component of the mathematical chemistry sciences. In chemical graph theory, a lot of graphical invariants have been used for obtaining correlations of chemical structures with various chemical reactivity, physical properties, or biological activity [1]. These graphical invariants are called topological indices of graphs in this field. There is a large family of distance or degree based topological indices of graphs in chemical graph theory. Also, we can say that the topological indices have been numerical parameters of a graph that are invariant under graph isomorphism. Research on the topological indices have been intensively rising recently. Topological indices have been the numerical indices based on the topology of the atoms and their bonds $[1,2]$. There are more than one hundred topological indices. They have characterized the physicochemical properties of the most of molecules. Molecules and molecular compounds are represented by graphs, where their atom types are called by vertices and also their bonds called by edges [3]. Furthermore, the topological indices also compute the vulnerability of a molecular graph same as the network vulnerability parameters [4].

Let $G=(V(G), E(G))$ be a graph of order $n$ and size $m$, where $n=|V(G)|$ and $m=|E(G)|$. Now, we will give some definitions that we need throughout this paper. For $v \in V(G)$, the open neighborhood of $v$ is defined by $N_{G}(v)=\{u \in V(G) \mid u v \in E(G)\}$ and also closed neighborhood of $v$ is defined by $N_{G}[v]=N_{G}(v) \cup\{v\}$. The degree of vertex $v$ in $G$ is the number of edges incident to $v$, also it is the size of its open neighborhood, and denoted by $\operatorname{deg}_{G}(v)$ [5]. Let $u$ and $v$ be any two vertices. The distance between $u$ and $v$ in the graph $G$ is the length of a shortest path between them, also is denoted by $d_{G}(u, v)$. The diameter $\operatorname{diam}(G)$ of a graph $G$ is defined the length of largest path which is the shortest path between any two vertices of $G$. The eccentricity value of vertex $u$ in $G$ denoted by $\varepsilon_{G}(u)$, that is the length of largest path between a vertex $u$ and any other vertex $v$ of $G$, 
$\varepsilon_{G}(u)=\max _{v \in V(G)} d_{G}(u, v)[6]$. Let $f=u v$ be an edge in $E(G)$. Then, the degree of the edge $f$, denoted by $\operatorname{deg}_{G}(f)$, is defined to be

$$
\operatorname{deg}_{G}(f)=\operatorname{deg}_{G}(u)+\operatorname{deg}_{G}(v)-2
$$

Let $f_{1}=u_{1} v_{1}$ and $f_{2}=u_{2} v_{2}$ be two edges in $E(G)$. The distance between $f_{1}$ and $f_{2}$, denoted by $d_{G}\left(f_{1}, f_{2}\right)$, is defined to:

$$
d_{G}\left(f_{1}, f_{2}\right)=\min \left\{d_{G}\left(u_{1}, u_{2}\right), d_{G}\left(u_{1}, v_{2}\right), d_{G}\left(v_{1}, u_{2}\right), d_{G}\left(v_{1}, v_{2}\right)\right\}
$$

The eccentricity value of edge $f$ in $G$, denoted by $\varepsilon_{G}(f)$ is defined as:

$$
\varepsilon_{G}(f)=\max \left\{d_{G}(f, e) \mid e \in E(G)\right\}[6] .
$$

Let $L_{n} \cong P_{n} \square P_{2}, n \geq 2$, be ladder with the vertex set $V\left(L_{n}\right)=\left\{v_{i}, u_{i}: i=1,2, \ldots, n\right\}$. Then, the edge set $E\left(L_{n}\right)=\left\{v_{i} v_{i+1}, u_{i} u_{i+1}: i=1,2, \ldots, n-1\right\} \cup$

$\left\{v_{i} u_{i}: i=1,2, \ldots, n\right\}$, see [7]. If we add the edges $u_{i} v_{i+1}, i=1,2, \ldots, n-1$, to the ladder $L_{n}$ and remove the vertex $u_{n}$ with both incident edges $u_{n-1} u_{n}$ and $u_{n} v_{n}$, then a triangular ladder $T L_{n}$ is obtained. A diamond graph $B r_{n}, n \geq 3$, is obtained by joining a single vertex $w$ to all vertices $v_{i}, i=1,2, \ldots, n$, of a triangular ladder $T L_{n}[8,9]$. The vertex set of $\mathrm{Br}_{\mathrm{n}}$ is $\mathrm{V}\left(\mathrm{Br}_{\mathrm{n}}\right)=\{\mathrm{w}\} \cup\left\{\mathrm{v}_{\mathrm{i}}: \mathrm{i}=1,2, \ldots, \mathrm{n}\right\} \cup\left\{\mathrm{u}_{\mathrm{i}}: \mathrm{i}=1,2, \ldots\right.$, $\mathrm{n}-1$ and the edge set is as follows:

$$
\begin{gathered}
E\left(B r_{n}\right)=\left\{u_{i} u_{i+1}: i=1,2, \ldots, n-2\right\} \\
U\left\{v_{i} v_{i+1}: i=1,2, \ldots, n-1\right\} \\
U\left\{u_{i} v_{i}: i=1,2, \ldots, n-1\right\} \\
U\left\{u_{i} v_{i+1}: i=1,2, \ldots, n-1\right\} \\
U\left\{w v_{i}: i=1,2, \ldots, n\right\} .
\end{gathered}
$$

Thus, $\left|\mathrm{V}\left(\mathrm{Br}_{\mathrm{n}}\right)\right|=2 \mathrm{n}$ and $\left|\mathrm{E}\left(\mathrm{Br}_{\mathrm{n}}\right)\right|=5 \mathrm{n}-5$ are obtained.

In Figure 1, we display the diamond graphs $B r_{3}$ and $B r_{4}$, and also the diamond graph $B r_{5}$ is shown in Figure 2 .

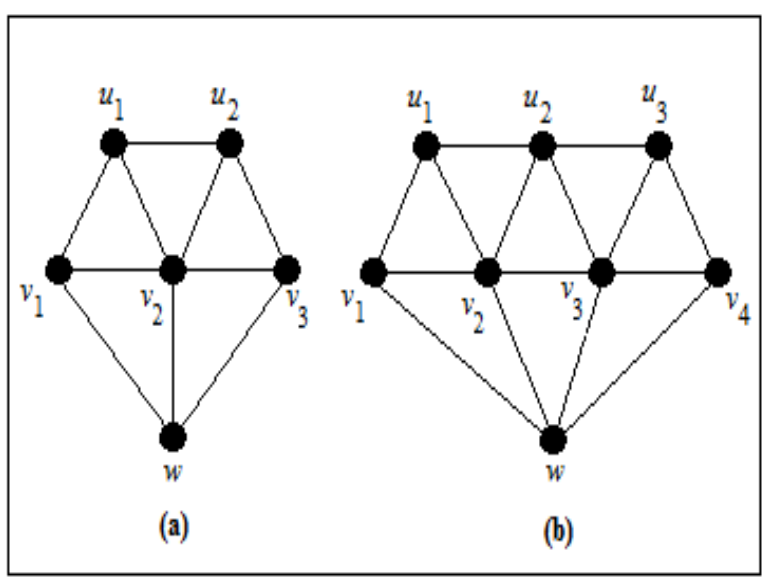

Figure 1. (a) The graph $B r_{3}$ (b) the graph $B r_{4}$

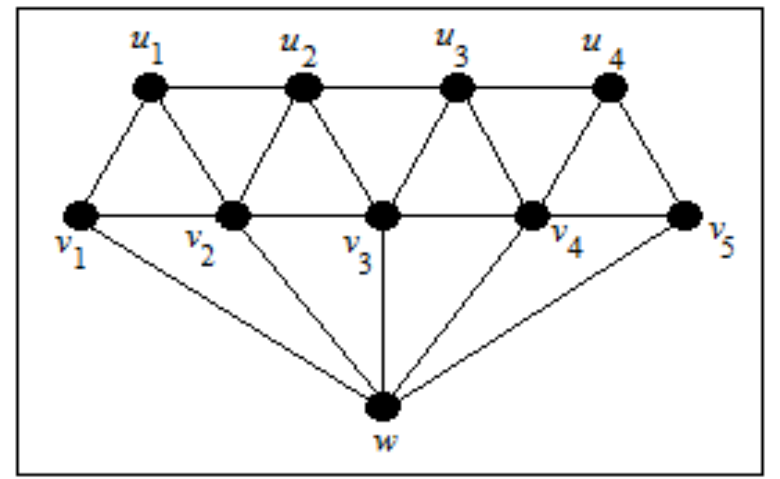

Figure 2. The graph $B r_{5}$

First topological index namely Wiener index in chemistry is developed by chemist Harold Wiener [1]. The aim of Wiener index is to the sum of half of the distances between every pair of vertices of $G$ and is defined as:

$$
W(G)=\frac{1}{2}\left(\sum_{i=1}^{n} \sum_{j=1}^{n} d_{G}\left(v_{i}, v_{j}\right)\right)
$$

There are a lot of topological indices were introduced after defined the wiener index, also they divided according to some properties of the graph. One of their most important ones is known that distance of any two vertices (or atoms) and edges (or bonds). In 2000, Gupta et al. [10] introduced new topological index namely connective eccentricity index denoted by $\xi^{c e}(G)$ for the graph $G$. It is defined with as follows:

$$
\xi^{c e}(G)=\sum_{u \varepsilon V(G)}\left(\operatorname{deg}_{G}(u) / \varepsilon_{G}(u)\right)
$$

The eccentric connectivity index $\xi^{c}(G)$ was defined by Sharma et al [11]. The eccentric connectivity index is denoted by $\xi^{c}(G)$ for the any graph $G$, also is defined as follows:

$$
\xi^{c}(G)=\sum_{u \varepsilon V(G)}\left(\operatorname{deg}_{G}(u) \cdot \varepsilon_{G}(u)\right)
$$

The first Zagreb index and second Zagreb index of graphs were defined by Gutman et al. $[12,13]$. Then the first and second Zagreb eccentricity indices $E_{1}(G)$ and $E_{2}(G)$ were defined by Vukicevic et al. [14]. The definitions of them are as follows:

and

$$
E_{1}(G)=\sum_{u \in V(G)}\left(\varepsilon_{G}(u)\right)^{2}
$$

$$
E_{2}(G)=\sum_{u v \in E(G)}\left(\varepsilon_{G}(u) \cdot \varepsilon_{G}(v)\right)
$$


In [6], the average eccentricity index for the any graph $G$ is defined as follows:

$$
\operatorname{avec}(G)=\frac{1}{|V(G)|} \sum_{u \in V(G)} \varepsilon_{G}(u)
$$

Recently, a new topological index namely edge eccentric connectivity index, has been studied. This new index was defined by Xu et al. [15] and has been studied by some authors $[16,17,18,19]$. The edge eccentric connectivity index of a graph $G$, denoted by $\xi_{e}^{c}(G)$, is defined as follows:

$$
\xi_{e}^{c}(G)=\sum_{f \in E(G)}\left(\operatorname{deg}_{G}(f) \cdot \varepsilon_{G}(f)\right)
$$

where $\varepsilon_{G}(f)$ is eccentricity value and $\operatorname{deg}_{G}(f)$ is degree of an edge $f$ in the graph $G$. Each eccentricity based indices have been much used recently in the QSAR/QSPR studies.

In this paper, some eccentricity-based topological indices such as connective eccentricity, eccentric connectivity, Zagreb eccentricity, average eccentricity and edge eccentric connectivity have been computed for the diamond graphs.

\section{The Exact Values of Eccentricity-Based Topological Indices of Diamond Graphs}

In this chapter, we compute the values of $\xi^{c e}\left(B r_{n}\right)$, $\xi^{c}\left(B r_{n}\right), E_{1}\left(B r_{n}\right), E_{2}\left(B r_{n}\right)$, avec $\left(B r_{n}\right)$ and $\xi_{e}^{c}\left(B r_{n}\right)$ for the diamond graph of order $2 n$. Firstly, we give the degrees of vertices and edges of $B r_{n}$. Then, we give a lemma for the diamond graphs.

The degrees of every vertex in the diamond graphs $B r_{n}$ are as follows:

$$
\begin{aligned}
& \operatorname{deg}_{B r_{n}}\left(u_{1}\right)=\operatorname{deg}_{B r_{n}}\left(u_{n-1}\right)=3, \\
& \operatorname{deg}_{B r_{n}}\left(u_{i}\right)=4, \text { where } 2 \leq i \leq n-2, \\
& \operatorname{deg}_{B r_{n}}\left(v_{1}\right)=\operatorname{deg}_{B r_{n}}\left(v_{n}\right)=3, \\
& \operatorname{deg}_{B r_{n}}\left(v_{i}\right)=5, \text { where } 2 \leq i \leq n-1, \\
& \operatorname{deg}_{B r_{n}}(w)=n .
\end{aligned}
$$

Furthermore, the edges of $B r_{5}$ are labeled in Figure 3.

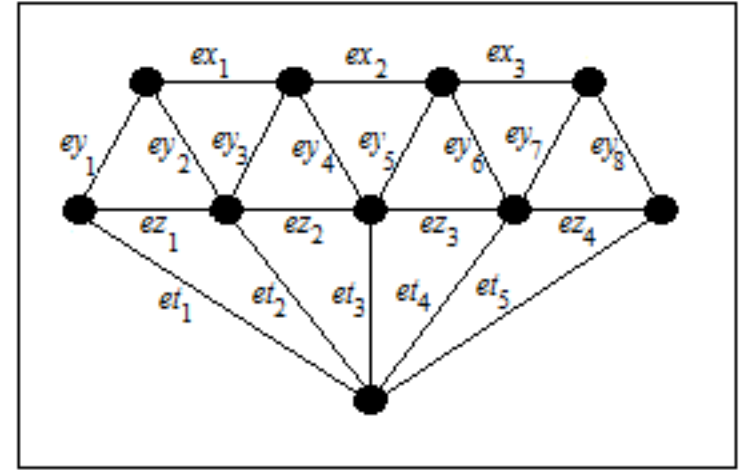

Figure 3. The graph $B r_{5}$ whose edges are labeled
The degrees of every edge in the diamond graphs $B r_{n}$ are as follows:

$$
\begin{aligned}
& \operatorname{deg}_{B r_{n}}\left(e x_{1}\right)=\operatorname{deg}_{B r_{n}}\left(e x_{n-2}\right)=5, \\
& \operatorname{deg}_{B r_{n}}\left(e x_{i}\right)=6, \text { where } 2 \leq i \leq n-3, \\
& \operatorname{deg}_{B r_{n}}\left(e y_{1}\right)=\operatorname{deg}_{B r_{n}}\left(e y_{2 n-2}\right)=4, \\
& \operatorname{deg}_{B r_{n}}\left(e y_{2}\right)=\operatorname{deg}_{B r_{n}}\left(e y_{2 n-3}\right)=6, \\
& \operatorname{deg}_{B r_{n}}\left(e y_{i}\right)=7, \text { where } 3 \leq i \leq 2 n-4, \\
& \operatorname{deg}_{B r_{n}}\left(e z_{1}\right)=\operatorname{deg}_{B r_{n}}\left(e z_{n-1}\right)=6, \\
& \operatorname{deg}_{B r_{n}}\left(e z_{i}\right)=8, \text { where } 2 \leq i \leq n-2, \\
& \operatorname{deg}_{B r_{n}}\left(e t_{1}\right)=\operatorname{deg}_{B r_{n}}\left(e t_{n}\right)=n+1, \\
& \operatorname{deg}_{B r_{n}}\left(e t_{i}\right)=n+3, \text { where } 2 \leq i \leq n-1 .
\end{aligned}
$$

Lemma 2.1. Let $B r_{n}$ be a diamond graph of order $2 n$. If $n \geq 6$, then $\operatorname{diam}\left(B r_{n}\right)=4$.

Proof. Let $V\left(B r_{n}\right)=V_{1}\left(B r_{n}\right) \cup V_{2}\left(B r_{n}\right) \cup\{w\}$, where $V_{1}\left(B r_{n}\right)=\left\{u_{1}, u_{2}, \ldots, u_{n-1}\right\} \quad$ and $\quad V_{2}\left(B r_{n}\right)=$ $\left\{v_{1}, v_{2}, \ldots, v_{n}\right\}$. These vertices can be seen in Figures 1 and 2. Firstly, we consider the vertex $w$. Clearly, $d_{B r_{n}}\left(u_{i}, w\right)=2$ and $d_{B r_{n}}\left(v_{i}, w\right)=1$ for each vertex $u_{i} \in V_{1}\left(B r_{n}\right)$ and $v_{i} \in V_{2}\left(B r_{n}\right)$, respectively. Then, we consider any two vertices as like $u_{i} \in V_{1}\left(B r_{n}\right)$ and $v_{i} \in V_{2}\left(B r_{n}\right)$. So, we have $d_{B r_{n}}\left(u_{i}, v_{x}\right) \leq 4$ and $d_{B r_{n}}\left(u_{i}, v_{y}\right) \leq 3$, where $v_{x} \in V_{1}\left(B r_{n}\right)-\left\{u_{i}\right\}$ and $v_{y} \in V_{2}\left(B r_{n}\right)$. Similarly, we have $d_{B r_{n}}\left(v_{i}, v_{z}\right) \leq 2$, where $v_{z} \in V_{2}\left(B r_{n}\right)-\left\{v_{i}\right\}$. Then, it is easy to see that $d_{B r_{n}}\left(u_{i}, u_{n-1}\right)=4$. Because, a path with 4-length such as $u_{1}, N_{B r_{n}}\left(u_{1}\right), w, N_{B r_{n}}\left(u_{n-1}\right), u_{n-1}$, where $N_{B r_{n}}\left(u_{1}\right)$, $N_{B r_{n}}\left(u_{n-1}\right) \in V_{2}\left(B r_{n}\right)$ can be found every time for $n \geq 6$. So, we get $\operatorname{diam}\left(B r_{n}\right)=4$.

Theorem 2.1 Let $B r_{n}$ be a diamond graph of order 2n. If $n \geq 9$, then $\xi^{c e}\left(B r_{n}\right)=\frac{19 n-17}{6}$.

Proof. Finding the eccentricity values of every vertex of $B r_{n}$ is very similar to Lemma 2.1. Due to $n \geq 9$, the eccentricity values of every vertex in the diamond graphs $\mathrm{Br}_{n}$ are as follows:

$\varepsilon_{B r_{n}}\left(u_{i}\right)=4$, where $1 \leq i \leq n-1$,

$\varepsilon_{B r_{n}}\left(v_{i}\right)=3$, where $1 \leq i \leq n$,

$\varepsilon_{B r_{n}}(w)=2$.

Then we get the following:

$$
\begin{aligned}
& \xi^{c e}\left(B r_{n}\right)=\sum_{u \in V\left(B r_{n}\right)}\left(\frac{\operatorname{deg}_{B r_{n}}(u)}{\varepsilon_{B r_{n}}(u)}\right) \\
& =\sum_{i=1}^{n-1}\left(\frac{\operatorname{deg}_{B r_{n}}\left(u_{i}\right)}{\varepsilon_{B r_{n}}\left(u_{i}\right)}\right)+\sum_{i=1}^{n}\left(\frac{\operatorname{deg}_{B r_{n}}\left(v_{i}\right)}{\varepsilon_{B r_{n}}\left(v_{i}\right)}\right)+\left(\frac{\operatorname{deg}_{B r_{n}}(w)}{\varepsilon_{B r_{n}}(w)}\right) \\
& =\left(\frac{2.3+(n-3) \cdot 4}{4}\right)+\left(\frac{2.3+(n-3) .5}{3}\right)+\left(\frac{n}{2}\right) \\
& =\frac{19 n-17}{6} .
\end{aligned}
$$


Theorem 2.2. Let $B r_{n}$ be a diamond graph of order 2n. If $n \geq 9$, then $\xi^{c}\left(B r_{n}\right)=33 n-36$.

Proof: The degree and eccentricity values of every vertex of $B r_{n}$ are found in the Theorem 2.1.

Thus, we have

$$
\begin{aligned}
& \xi^{c}\left(B r_{n}\right)=\sum_{u \varepsilon V\left(B r_{n}\right)}\left(\operatorname{deg}_{B r_{n}}(u) \cdot \varepsilon_{B r_{n}}(u)\right) \\
& =\sum_{i=1}^{n-1}\left(\operatorname{deg}_{B r_{n}}\left(u_{i}\right) \cdot \varepsilon_{B r_{n}}\left(u_{i}\right)\right)+\sum_{i=1}^{n}\left(\operatorname{deg}_{B r_{n}}\left(v_{i}\right) \cdot \varepsilon_{B r_{n}}\left(v_{i}\right)\right) \\
& \quad+\left(\operatorname{deg}_{B r_{n}}(w) \cdot \varepsilon_{B r_{n}}(w)\right) \\
& =(2 \cdot(3.4)+(n-3) \cdot(4 \cdot 4))+(2 \cdot(3 \cdot 3)+(n-2) \cdot(5 \cdot 3)) \\
& \quad+2 n \\
& =33 n-36 .
\end{aligned}
$$

Theorem 2.3. Let $B r_{n}$ be a diamond graph of order 2n. If $n \geq 9$, then $E_{1}\left(B r_{n}\right)=25 n-12$ and also if $n \geq 12$, then $E_{2}\left(B r_{n}\right)=55 n-65$.

Proof: The degrees and eccentricity values of every vertex of $B r_{n}$ are found in the Theorem 2.1.

Thus, we have

$$
\begin{aligned}
& E_{1}\left(B r_{n}\right)=\sum_{u \in V\left(B r_{n}\right)}\left(\varepsilon_{B r_{n}}(u)\right)^{2} \\
& =\sum_{i=1}^{n-1}\left(\varepsilon_{B r_{n}}\left(u_{i}\right)\right)^{2}+\sum_{i=1}^{n}\left(\varepsilon_{B r_{n}}\left(v_{i}\right)\right)^{2}+\left(\varepsilon_{B r_{n}}(w)\right)^{2} \\
& =\left((n-1) \cdot 4^{2}\right)+\left(n \cdot 3^{2}\right)+2^{2} \\
& =25 n-12 .
\end{aligned}
$$

Clearly, in the graph $B r_{n}$ the numbers of edges $e x_{i}$, $e y_{i}, e z_{i}$ and $e t_{i}$ are $n-2,2 n-2, n-1$ and $n$, respectively.

Thus, we have

$$
\begin{aligned}
& E_{2}\left(B r_{n}\right)=\sum_{u v \in E\left(B r_{n}\right)}\left(\varepsilon_{B r_{n}}(u) \cdot \varepsilon_{B r_{n}}(v)\right) \\
& =\sum_{i=1}^{n-2}\left(\varepsilon_{B r_{n}}(u) \cdot \varepsilon_{B r_{n}}(u)\right)+\sum_{i=1}^{2 n-2}\left(\varepsilon_{B r_{n}}(u) \cdot \varepsilon_{B r_{n}}(v)\right) \\
& +\sum_{i=1}^{n-1}\left(\varepsilon_{B r_{n}}(v) \cdot \varepsilon_{B r_{n}}(v)\right)+\sum_{i=1}^{n}\left(\varepsilon_{B r_{n}}(v) \cdot \varepsilon_{B r_{n}}(w)\right) \\
& =((n-2) \cdot(4 \cdot 4))+((2 n-2) \cdot(4 \cdot 3))+((n-1) . \\
& \quad+(n \cdot(3 \cdot 2)) \\
& =55 n-65 .
\end{aligned}
$$

Theorem 2.4. Let $B r_{n}$ be a diamond graph of order 2n. If $n \geq 9$, then $\operatorname{avec}\left(B r_{n}\right)=\frac{7}{2}-\frac{1}{n}$.

Proof. The degree and eccentricity values of every vertex of $\mathrm{Br}_{n}$ are found in the Theorem 2.1.

Then, we get

$$
\begin{aligned}
& \operatorname{avec}\left(B r_{n}\right)=\frac{1}{\left|V\left(B r_{n}\right)\right|} \sum_{u \in V\left(B r_{n}\right)} \varepsilon_{B r_{n}}(u) \\
& =\frac{1}{2 n}\left(\sum_{i=1}^{n-1}\left(\varepsilon_{B r_{n}}\left(u_{i}\right)\right)+\sum_{i=1}^{n}\left(\varepsilon_{B r_{n}}\left(v_{i}\right)\right)+\left(\varepsilon_{B r_{n}}(w)\right)\right) \\
& =\frac{1}{2 n}((n-1) \cdot 4+n \cdot 3+2) \\
& =\frac{7}{2}-\frac{1}{n} .
\end{aligned}
$$

Theorem 2.5. Let $B r_{n}$ be a diamond graph of order 2n. If $n \geq 12$, then $\xi_{e}^{c}\left(B r_{n}\right)=2 n^{2}+96 n-166$.

Proof. The degrees of every edge of $B r_{n}$ are given at the beginning of the Section 2. For $n \geq 12$, the eccentricity values of every edge of $B r_{n}$ can be found similar to Theorem 2.1.

Clearly, the eccentricity values of every edge of $B r_{n}$ are as follows:

$\varepsilon_{B r_{n}}\left(\right.$ ex $\left._{i}\right)=4$, where $1 \leq i \leq n-2$,

$\varepsilon_{B r_{n}}\left(e y_{i}\right)=3$, where $1 \leq i \leq 2 n-2$,

$\varepsilon_{B r_{n}}\left(e z_{i}\right)=3$, where $1 \leq i \leq n-1$,

$\varepsilon_{B r_{n}}\left(e t_{i}\right)=2$, where $1 \leq i \leq n$.

Thus, we have

$$
\begin{aligned}
& \xi_{e}^{c}\left(B r_{n}\right)=\sum_{f \in E\left(B r_{n}\right)}\left(\operatorname{deg}_{B r_{n}}(f) \cdot \varepsilon_{B r_{n}}(f)\right) \\
& =\sum_{i=1}^{n-2}\left(\operatorname{deg}_{B r_{n}}\left(e x_{i}\right) \cdot \varepsilon_{B r_{n}}\left(e x_{i}\right)\right) \\
& +\sum_{i=1}^{2 n-2}\left(\operatorname{deg}_{B r_{n}}\left(e y_{i}\right) \cdot \varepsilon_{B r_{n}}\left(e y_{i}\right)\right) \\
& +\sum_{i=1}^{n-1}\left(\operatorname{deg}_{B r_{n}}\left(e z_{i}\right) \cdot \varepsilon_{B r_{n}}\left(e z_{i}\right)\right) \\
& \quad+\sum_{i=1}^{n}\left(\operatorname{deg}_{B r_{n}}\left(e t_{i}\right) \cdot \varepsilon_{B r_{n}}\left(e t_{i}\right)\right) \\
& =(2 .(4.5)+(n-4) \cdot(4 \cdot 6)) \\
& +(2 .(3.4)+2 \cdot(3.6)+(2 n-6) \cdot(3.7)) \\
& \quad+(2 .(3.6)+(n-3) \cdot(3.8)) \\
& \quad+(2 \cdot(2 \cdot(n+1))+(n-2) \cdot(2 \cdot(n+3))) \\
& =2 n^{2}+96 n-166 . \quad \text { a }
\end{aligned}
$$


Next, the vertex eccentricity-based topological indices of diamond graphs for $n \leq 8$ and the edge eccentricity-based topological indices of diamond graphs for $n \leq 11$ are given in Tables 1 and 2, respectively.

Table 1. Some vertex eccentricity-based topological indices of diamond graphs for $n \leq 8$.

\begin{tabular}{|c|c|c|c|c|}
\hline & $\xi^{c e}\left(B r_{n}\right)$ & $\xi^{c}\left(B r_{n}\right)$ & $E_{1}\left(B r_{n}\right)$ & $\operatorname{avec}\left(B r_{n}\right)$ \\
\hline$n=3$ & $25 / 2$ & 35 & 21 & $11 / 6$ \\
\hline$n=4$ & 13 & 72 & 52 & $5 / 2$ \\
\hline$n=5$ & 15 & 110 & 80 & $14 / 5$ \\
\hline$n=6$ & $103 / 6$ & 150 & 117 & $37 / 12$ \\
\hline$n=7$ & 20 & 187 & 149 & $45 / 14$ \\
\hline$n=8$ & $137 / 6$ & 224 & 181 & $53 / 16$ \\
\hline
\end{tabular}

Table 2. Some edge eccentricity-based topological indices of diamond graphs for $n \leq 11$.

\begin{tabular}{|c|c|c|}
\hline & $E_{2}\left(B r_{n}\right)$ & $\xi_{e}^{c}\left(B r_{n}\right)$ \\
\hline$n=3$ & 30 & 50 \\
\hline$n=4$ & 86 & 140 \\
\hline$n=5$ & 151 & 248 \\
\hline$n=6$ & 225 & 382 \\
\hline$n=7$ & 293 & 526 \\
\hline$n=8$ & 361 & 684 \\
\hline$n=9$ & 430 & 842 \\
\hline$n=10$ & 485 & 982 \\
\hline$n=11$ & 540 & 1126 \\
\hline
\end{tabular}

\section{Conclusion}

Eccentricity-based topological indices in diamond graphs are considered in this paper while giving an insight of how to evaluate the parameters and derive formulas on diamond graphs. Moreover, we give a lemma for diamond graphs such as diameter of $B r_{n}$ is 4 for $n \geq 6$.

\section{Acknowledgment}

The author is grateful to the area editor and the anonymous referees for their constructive comments and valuable suggestions which have helped me very much to improve the paper.

\section{References}

[1] Wiener, H. 1947. Structrual determination of paraffin boiling points. Journal of the American Chemical Society, 69(1), 17-20.

[2] Dobrynin A. A., Entringer, R. , Gutman, I., 2001. Wiener index of trees: theory and applications. Acta Applicandae Mathematicae, 66 , 211-249.

[3] Todeschini R., Consonni, V. 2000. Handbook of Molecular Descriptors. Wiley-VCH Verlag GmbH\&Co. KGaA, Weinheim, 668s.

[4] Turacl, T. 2016. Zagreb Eccentricity Indices of Cycles Related Graphs. Ars Combinatoria, 125, 247-256.

[5] West, D.B. 1996. Introduction to Graph Theory, 2nd edition. Prentice Hall, Upper Saddle, River, 512 s.
[6] Harary F., Buckley, F. 1989. Distance in Graphs. Addison-Wesley Publishing Company, 352s.

[7] Gallian, J.A. 2014. Graph labeling, Electronic Journal of Combinatorics, 17, (Dynamic Survey \#DS6).

[8] Shulhany, M.A., Salman, A.N.M. 2015. Bilangan Terhubung Pelangi Graf Berlian. Prosiding Seminar Nasional Matematika dan Pendidikan Matematika, UMS( 2015), 916-924.

[9] Hinding, N., Firmayasari, D., Basir, H., Bača, M. and Feňovčíková, A.S. 2017. On irregularity strength of diamond network. AKCE International Journal of Graphs and Combinatorics,Doi: 10.1016/j.akcej.2017.10.003

[10] Gupta, S, Singh, M., Madan, A.K. 2000. Connective eccentricity index: a novel topological descriptor for predicting biological activity. Journal of Molecular Graphics and Modelling, 18(1), 18-25.

[11] Sharma, V., Goswami, R., Madan, A.K. 1997. Eccentric connectivity index: A novel highly discriminating topological descriptor for structure-property and structure-activity studies. Journal of Molecular Graphics and Modelling, 37(2), 273-282.

[12] Gutman, I., Trinajstic, N. 1972 Graph theory and molecular orbitals. III. Total _-electron energy of alternant hydrocarbons. Chemical Physics Letters, 17, 535-538.

[13] Gutman, I., Ruscic, B., Trinajstic, N., Wilcox, C.F. 1975. Graph theory and molecular orbitals. XII. Acyclic polyenes. Journal of Chemical Physics, 62, 3399-3405.

[14] Vukicevic, D., Graovac, A. 2010. Note on the comparison of the first and second normalized Zagreb eccentricity indices. Acta Chimica Slovenica, 57, 524-528.

[15] Xu, X., Guo, Y. 2012. The Edge Version of Eccentric Connectivity Index. International Mathematical Forum, 7, 273-280.

[16] Odabas, Z.N. 2013. The Edge Eccentric Connectivity Index of Dendrimers, Journal of Computational and Theoretical Nanoscience, 10(4), 783-784.

[17] Berberler, Z.N., Berberler, M.E. 2016. Edge eccentric connectivity index of nanothorns. Bulgarian Chemical Communications, 48(1), 165-170.

[18] Turacl, T., Ökten, M. 2015. The Edge Eccentric Connectivity Index of Hexagonal Cactus Chains. Journal of Computational and Theoretical Nanoscience, 12(10), 3977-3980.

[19] Aslan, E. 2015. The Edge Eccentric Connectivity Index of Armchair Polyhex Nanotubes. Journal of Computational and Theoretical Nanoscience, 12(11), 4455-4458. 